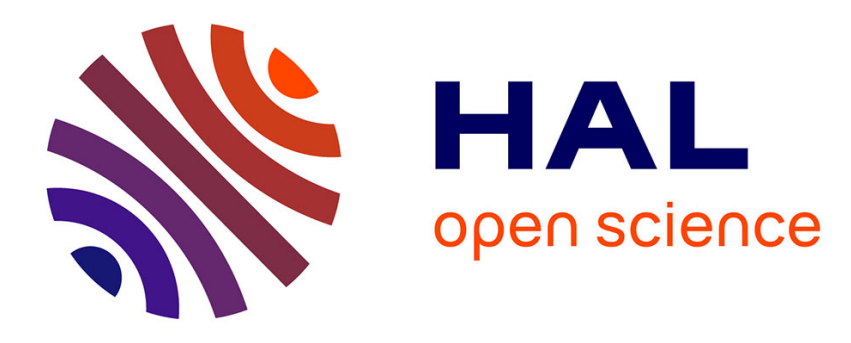

\title{
Herrschernamen als Legitimationsinstrument im frühmittelalterlichen Indien (6. bis 10. Jahrhundert)
}

\author{
Annette Schmiedchen
}

\section{To cite this version:}

Annette Schmiedchen. Herrschernamen als Legitimationsinstrument im frühmittelalterlichen Indien (6. bis 10. Jahrhundert). Machterhalt und Herrschaftssicherung, 8, V\&R unipress, pp.175-192, 2019, Macht und Herrschaft, 978-3-8471-1084-2. 10.14220/9783737010849.175 . hal-03012193

\section{HAL Id: hal-03012193 https://hal.science/hal-03012193}

Submitted on 3 Dec 2020

HAL is a multi-disciplinary open access archive for the deposit and dissemination of scientific research documents, whether they are published or not. The documents may come from teaching and research institutions in France or abroad, or from public or private research centers.
L'archive ouverte pluridisciplinaire HAL, est destinée au dépôt et à la diffusion de documents scientifiques de niveau recherche, publiés ou non, émanant des établissements d'enseignement et de recherche français ou étrangers, des laboratoires publics ou privés. 
Matthias Becher/Hendrik Hess (Hg.)

\section{Machterhalt und Herrschaftssicherung}

Namen als Legitimationsinstrument in transkultureller Perspektive

\section{Bonn University Press}

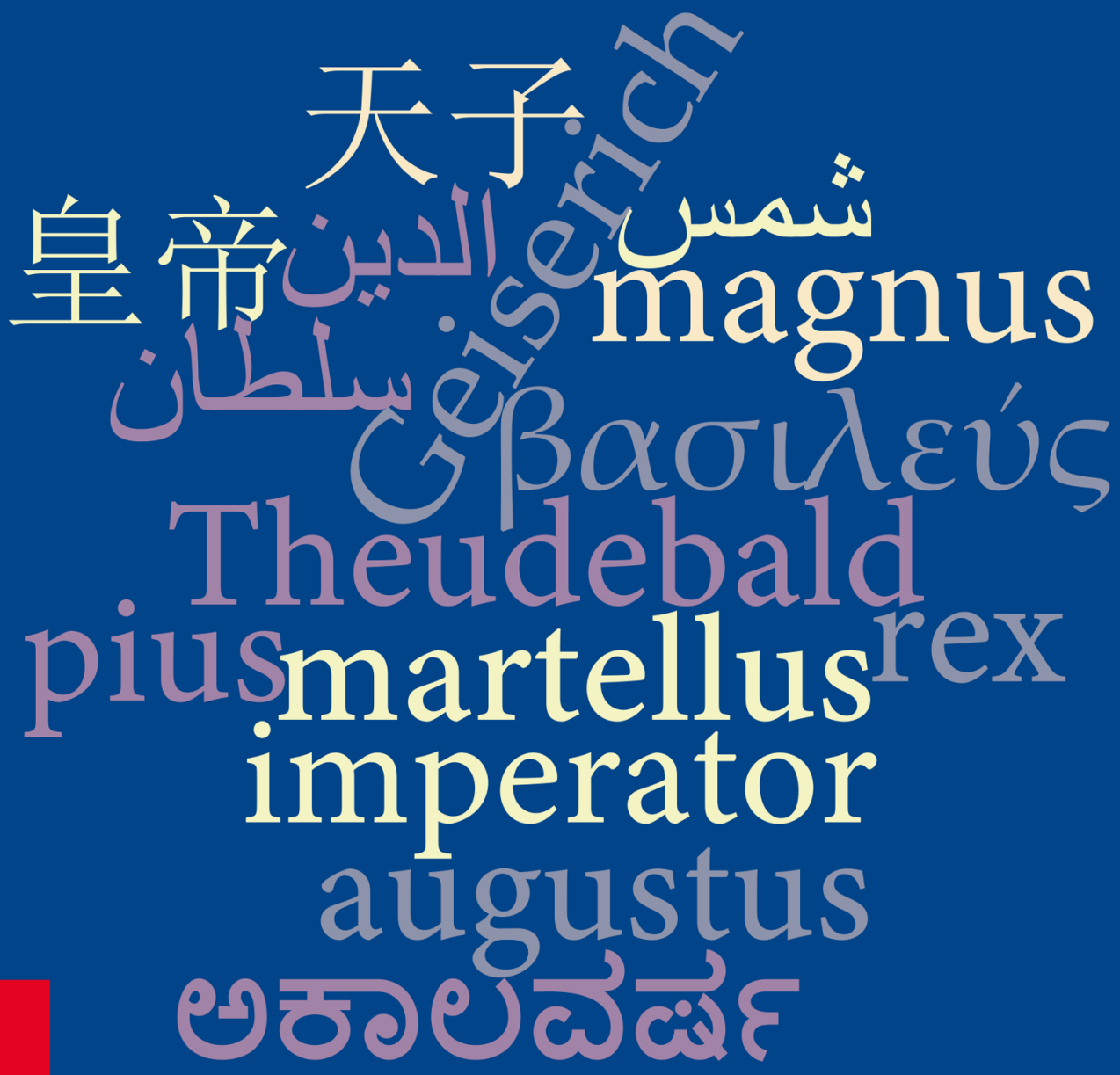

V\&R unipress 


\section{Macht und Herrschaft}

Schriftenreihe des SFB 1167

»Macht und Herrschaft - Vormoderne Konfigurationen in transkultureller Perspektive»

Band 8

Herausgegeben von

Matthias Becher, Elke Brüggen und Stephan Conermann 
Matthias Becher / Hendrik Hess (Hg.)

\section{Machterhalt und Herrschaftssicherung}

Namen als Legitimationsinstrument in

transkultureller Perspektive

Mit 13 Abbildungen

V\&R unipress

Bonn University Press 


\section{UNIVERSITÄT BONN

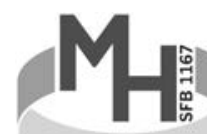

DFG

Bibliografische Information der Deutschen Nationalbibliothek

Die Deutsche Nationalbibliothek verzeichnet diese Publikation in der Deutschen

Nationalbibliografie; detaillierte bibliografische Daten sind im Internet über

https://dnb.d-nb.de abrufbar.

Veröffentlichungen der Bonn University Press

erscheinen im Verlag V\&R unipress GmbH.

Gedruckt mit freundlicher Unterstützung der Deutschen Forschungsgemeinschaft.

(C) 2019, V\&R unipress GmbH, Robert-Bosch-Breite 6, D-37079 Göttingen

Alle Rechte vorbehalten. Das Werk und seine Teile sind urheberrechtlich geschützt.

Jede Verwertung in anderen als den gesetzlich zugelassenen Fällen bedarf der vorherigen schriftlichen Einwilligung des Verlages.

Umschlagabbildung: Erstellt mit Voyant Tools, Stéfan Sinclair \& Geoffrey Rockwell (๑ 2019)

Privacy v. 2.4 (M29).

Vandenhoeck \& Ruprecht Verlage | www.vandenhoeck-ruprecht-verlage.com

ISSN 2511-0004

ISBN 978-3-8470-1084-5 


\section{Inhalt}

Vorwort zur Schriftenreihe ................. 7

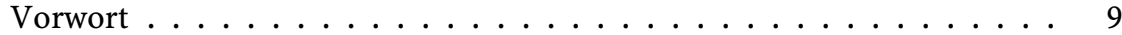

Matthias Becher / Hendrik Hess

Einleitung ........................ 11

Christian Vogel

Nomen regis - Herrschaftstheorie zwischen Definition und Legitimation . 19

Mike Janßen

Für den König beten - Eine frühmittelalterliche Legitimationsstrategie . . 39

Christian Schwermann

Schlechte Namen, Leserlenkung und Herrscherkritik in antiken

chinesischen Texten . . . . . . . . . . . . . . . 75

Matthias Becher

Die Nachbenennung bei den frühen Karolingern. Familiäres

Selbstverständnis versus politische Opportunität . . . . . . . . . . . . . 129

Laury Sarti

Die Namen zukünftiger Herrscher. Die Vergabepraxis im byzantinischen

Osten und dem karolingischen Westen im Vergleich (717-905) . . . . . . 151

Annette Schmiedchen

Herrschernamen als Legitimationsinstrument im frühmittelalterlichen

Indien (6. bis 10. Jahrhundert) . . . . . . . . . . . . . 175 
Tilmann Trausch

Aibak, 'Alī, Alexander. Namen als Beitrag zur Herrscherlegitimation im

Sultanat von Delhi . . . . . . . . . . . . . . . . . 193

Wolfgang Haubrichs

Funktion und Performanz. Namen als Instrumente der Sicherung von

Herrschaft und Identität im frühen Mittelalter Westeuropas . . . . . . . . 235

Dieter Geuenich

Beispiele programmatischer Namengebung in frühmittelalterlichen

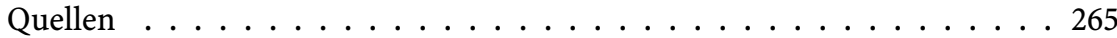

Hendrik Hess

Namengebung und die römische Oberschicht in Gallien zwischen

imperium und regna im 5. und 6. Jahrhundert

Christoph Haack

Namen und Narrative. Ein Versuch zur ethnischen Interpretation

frühmittelalterlicher Personennamen und der »Angelsächsischen

Mission« auf Grundlage der Datenbank »Nomen et Gens» . . . . . . . . . 315

Liste der AutorInnen . . . . . . . . . . . . . . . . 341

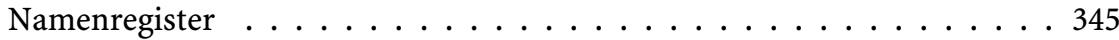




\title{
Herrschernamen als Legitimationsinstrument im frühmittelalterlichen Indien (6. bis 10. Jahrhundert)
}

\begin{abstract}
Royal names served the legitimation of rule and power in early medieval India. The naming conventions of the West Indian dynasty of the Maitrakas $\left(6^{\text {th }}-8^{\text {th }}\right.$ centuries) illustrate their anxiety to homogenise royal names and epithets for the sake of dynastic continuity, as well as the use of coronation names from the $7^{\text {th }}$ century onwards. Under the central Indian Rāstrakūtas ( $8^{\text {th }}-10^{\text {th }}$ centuries), it becomes even clearer that royal names and epithets were related to the concept of an ideal Indian ruler. The specific Rāstrakūța king names ending in ${ }^{\circ}$ varșa ("rain[ing] ") allude to their great munificence. Several religiously connoted epithets, which were introduced in the $10^{\text {th }}$ century and might be also regarded as coronation names, show the endeavour to effectively tie this dynasty's history to the world of the gods.
\end{abstract}

Oskar von Hinüber beklagte 1980, dass "zur Erforschung der indischen Namen kaum die Grundlagen gelegt « seien. ${ }^{1}$ Rüdiger Schmitt konstatierte 1995, dass diese Klage noch immer aktuell sei; ${ }^{2}$ und auch seither hat sich der Forschungsstand nicht grundlegend geändert.

Prinzipiell stehen für die Namensforschung zum vormodernen Indien ebenso wie für viele andere Forschungsfelder - zwei Quellengattungen zur Verfügung: normative Texte und Texte aus der Praxis. Zu den normativen Texten zählen in diesem Zusammenhang vor allem die `Gṛhyasūtras`, die zu den sogenannten >Vedāngas`, den »Gliedern des Veda« gehören und der indischen Tradition nicht mehr als Offenbarung ('́ruti), sondern nur als Überlieferung (smrti) gelten. ${ }^{3}$ Die `Gṛhyasūtras` lehren das Hausritual (abgeleitet von grha $=$ »Haus«) und stellen Geschichtsquellen von erstrangiger Bedeutung dar. Sie geben um-

1 Oskar von HINÜBER, Die Kolophone der Gilgit-Handschriften, in: Studien zur Indologie und Iranistik 5/6 (1980), 49-82, hier 53.

2 Rüdiger Schмiтt, Alt- und mittelindoarische Namen, in: Ernst Eichler et al. (edd.), Namenforschung. Ein internationales Handbuch zur Onomastik (Handbücher zur Sprach- und Kommunikationswissenschaft 11), Bd. 1, Berlin/New York 1995, 645-657, hier 645.

3 Klaus Mylıus, Geschichte der Literatur im alten Indien (Reclam-Reihe 1021), Leipzig 1983, 87-90. 
fassend Auskunft über die Lebensführung im alten Indien: von der Empfängnis über die Namensgebung, Initiationsriten, die Hochzeit bis hin zum Totenkult. Wie für zahlreiche andere Quellengattungen ist auch die Datierung der 'Gṛhyasūtrası problematisch. Sicher ist jedoch, dass sie bereits im indischen Altertum, d.h. bis spätestens zur Gupta-Zeit, entstanden sind.

Nach indischem Verständnis wohnt dem Namen magische Kraft inne, und der Name ist ein wesenhafter Teil seines Trägers. Der Name wird dem Kind in einem zeremoniellen Vorgang gegeben, und es finden sich sehr detaillierte Vorschriften über Form und Inhalt der Namen für Neugeborene. Auch andere Aspekte der Namensgebung (nāmakarana) werden in den Texten behandelt, beispielsweise der geeignete Zeitpunkt für diesen $\mathrm{Akt}^{4}{ }^{4}$

Für die Frage, inwiefern Namen als Legitimationsinstrumente dienen konnten, bietet sich ein gezielter Blick auf Herrschernamen an. Hier soll es exemplarisch um indische Königsnamen (in Sanskrit) aus dem frühmittelalterlichen West- und Zentralindien gehen. Inschriften stellen die für solche Untersuchungen prädestinierten Praxistexte dar. Die ungefähr 120 bekannten Kupfertafelurkunden der Maitraka-Dynastie aus Gujarat (6.-8. Jahrhundert) und die etwa 75 erhaltenen Kupfertafelurkunden der Rāștrakūṭa-Dynastie aus Gujarat und Maharashtra (8.-10. Jahrhundert) sind für die folgenden Ausführungen ausgewertet worden. Auf Kupferplatten eingravierte Inschriften dokumentieren in der Regel religiöse Stiftungen von Königen. Neben Stiftungsdetails enthält dieser Inschriftentypus Herrschertitulaturen und Königsgenealogien.

Auch für Indien ist die Sitte belegt, dass Herrscher bei Regierungsantritt einen >Thronnamen annahmen. R. Schmitt erwähnt in diesem Kontext den Beinamen "Aśoka» (»Ohneleid«) für den altindischen Maurya-König Priyadarśin (Prakrit: Piyadassi). ${ }^{5}$ Normative Vorgaben zu der Verwendung von Krönungsnamen scheinen aber nicht überliefert zu sein. Personennamen - insbesondere die von Herrschern - sollten von dem Namen einer Gottheit oder eines Weisen abgeleitet sein. ${ }^{6}$ Zweistämmige Vollnamen sind bei den Königsnamen besonders typisch; die Verkürzung zu Kurzformen, d.h. der Wegfall des Vorder- oder Hintergliedes, war ebenfalls möglich. ${ }^{7}$ Die vergebenen Namen sollten denen der Vorfahren ähneln; diese Regel galt wohl insbesondere für Königsnamen. Auch war die beispielsweise für die Gupta-Dynastie belegte Nachbenennung eines Enkels nach dem betreffenden Großvater im vormodernen Indien nicht untypisch. ${ }^{8}$

R. Schmitt hat mit Bezug auf Rudolf Otto Franke festgestellt: „Die semantische Analyse der Namen nach ihrem Inhalt ist von vorneherein dadurch erschwert,

\footnotetext{
4 Sснмiтt 1995, 647.

5 Ebd., 648f.

6 Ebd., 648.

7 Ebd., 649.

8 Ebd., 648.
} 
daß nicht alle bezeugten Namen analysiert werden können und `bedeutungsvoll sind. Insbesondere eine Namenwahl, die familiäre Bindungen betont [...] durch Nachbenennung nach früheren Familienmitgliedern oder durch Wiederholung eines Namenelementes und die folglich Gestalt annimmt in >diachronischen [...] bzw. `synchronischen`Zeugnissen einer Teilidentität von Namen [...], ist bekanntlich für das Aufkommen von Namenformen verantwortlich, deren Elemente sin durchaus keiner logischen Beziehung zu einander zu stehen brauchen, sondern ohne Rücksichtnahme auf den Sinn ganz willkürlich an einander gefügt werden können ${ }^{9}{ }^{9}$

Diese Phänomene seien zunächst am epigraphischen Material der Maitrakas vom frühen 6. bis zum zweiten Drittel des 8. Jahrhunderts untersucht, deren Inschriften bis auf einige Schutz- und Fluchverse am Ende durchgängig in Prosa verfasst sind. In den am Anfang stehenden Prosagenealogien wird ein Abriss der Dynastiegeschichte gegeben, wobei diese Passagen im Verlaufe der MaitrakaHerrschaft mehrfach modifiziert wurden, und dies zumindest partiell auf eine Weise, dass sich die Stammbaumkonstruktion mitunter schwierig gestaltet. Aus den ca. 120 bekannten Kupfertafelurkunden der Maitrakas ergibt sich eine Abfolge von insgesamt 19 Herrschern, die jedoch nicht alle eigene Urkunden hinterlassen haben. Zudem nennen die Genealogien einige Dynastiemitglieder, die nicht regiert haben. Namen, Beinamen und Titel der Könige sind auch in den Titulaturen belegt, die sich an die Genealogie anschließen. ${ }^{10}$

Bis zur Mitte des 7. Jahrhunderts wirken die urkundlich bezeugten Namen der Maitraka-Könige, bei denen ein starker Hang zur Sekundogenitur sichtbar ist, noch recht zufällig. Vom Dynastiegründer Bhațakka sind keine eigenen Urkunden überliefert. Sein Name ist nur aus den Inschriften seiner Nachfolger bekannt, und zwar zunächst in der Prakrit-Form »Bhatakka« und erst später in der sanskritisierten Version "Bhațārka«, einem aus bhața, "Soldat, Krieger«, und arka, "Sonne«, gebildeten Kompositum. ${ }^{11}$ Für die Nachkommen des Bhațakka / Bhațārka sind mehrere Namen mit dem zweiten Glied ${ }^{\circ}$ sena belegt (abgeleitet von Femininum senā, »Heer«), das im alten und mittelalterlichen Indien ein produktives Namensbildungselement darstellte: "Dharasena» $(4 \mathrm{x})$, "Dhruvasena» $(3 \mathrm{x})$ und »Guhasena $\lll(1 \mathrm{x}) .^{12}$

9 Ebd., 650.

10 Vgl. Annette Schmiedchen, Kings, Authors, and Messengers: The Composition of the Maitraka Copper-Plate Charters, in: Bharati Shelat/Thomas PARMAR (edd.), New Horizons in Indology (Prof. Dr. H. G. Shastri Commemoration Volume), Ahmedabad 2018, 35-41.

11 Monier Monier-Wiliams, A Sanskrit-English Dictionary, Oxford 1899, 89: »arka, the sun«; 745: »bhața, a mercenary, hired soldier, warrior«; »bhațārka, N. of the founder of the Valabhi dynasty«.

$12 \mathrm{Zu}$ Namen auf 'sena vgl. Schmitt 1995, 648-650; Oskar von HinüBER, Indische Namen in Zentralasien bis 1000 n.Chr., in: Ernst EICHLER et al. (edd.), Namenforschung. Ein internationales Handbuch zur Onomastik (Handbücher zur Sprach- und Kommunikationswissen- 


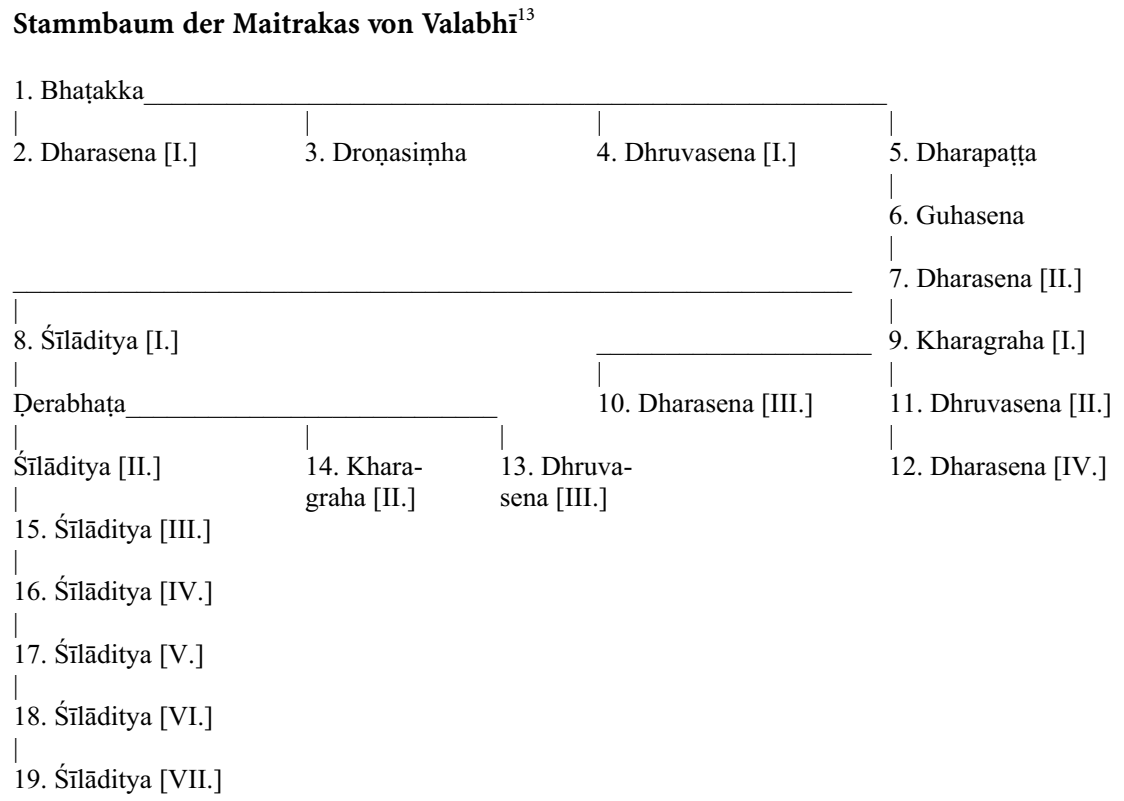

Für weitere belegte Königsnamen aus der frühen Maitraka-Zeit müsste wohl Rüdiger Schmitts oben erwähntes Argument in Anspruch genommen werden, »daß nicht alle bezeugten Namen analysiert werden können und ‘bedeutungsvoll« sind «. ${ }^{14}$ Auch wäre denkbar, dass es sich wie bei »Bhațakka« > »Bhatāarka» um Versuche der Sanskritisierung von mittelindischen Prakrit-Namen handelte. Zwei Könige hießen "Kharagraha", gebildet aus khara, "Esel«, und graha, »ergreifend, fassend«. Je einmal im Stammbaum erscheinen die Königsnamen "Droṇasiṃha (aus droṇa, »Trog «, ${ }^{15}$ und simhha, »Löwe«) und Dharapatța (aus dhara, »Berg", und patta $=$ "Tafel, Platte; Stirnschmuck») und der Nicht-Sanskrit-Name Derabhața (mit dem produktiven zweiten Glied ${ }^{\circ} b h a t a$, das in vielen Sanskritnamen belegt ist). ${ }^{16}$

schaft 11), Bd. 1, Berlin/New York 1995, 661-663. Das erste Glied dhara ${ }^{\circ}$ bedeutet »tragend, haltend" und »Berg» und kann auch für die Götter Kṛṣna und Śiva stehen; dhruva ${ }^{\circ}$ bedeutet "feststehend, dauerhaft« und ebenfalls »Berg« und kann auch für Brahman, Viṣnu oder Śiva stehen; $g u h a^{\circ}$ bedeutet »heiliger Platz« und kann auch für Skanda, Śiva, Viṣnu stehen.

13 Die Urkunden selbst enthalten keine Nummerierung der Könige; diese ist sekundär.

14 Siehe oben, Anm. 9.

15 "Drona» ist auch der Name einer Figur aus dem altindischen Epos `Mahābhārata‘, und zwar der Name des berühmten gemeinsamen Waffenlehrers der späteren Kontrahenten, der Pāndavas und der Kauravas.

16 Unter den Maitrakas trugen auch zwei ihrer wichtigsten Urkundenverfasser einen Namen auf `bhața, und zwar »Skandabhața", wörtlich »Soldat des [Kriegsgottes] Skanda«; vgl. SCHMIEDCHEN 2018, 37f. 
Im frühen 7. Jahrhundert taucht im Maitraka-Stammbaum erstmals der Name "Śīlāditya" auf, der bewusst aus śila, "Ehrenhaftigkeit, guter Charakter», und āditya, "Sonne« komponiert scheint. Ab Śīāditya [III.], d.h. seit der zweiten Hälfte des 7. Jahrhunderts, trugen sogar alle weiteren Maitraka-Könige den Namen "Śīlāditya«. Aus dem Umstand könnte man schließen, dass es sich bei "Śīlāditya« seit der Mitte des 7. Jahrhunderts um einen ausgesprochenen Krönungsnamen handelte. Für eine solche Interpretation spricht auch ein anderer Umstand: In königlichen Urkunden wird regelmäßig ein sogenannter »Bote« genannt, der augenscheinlich eine wichtige Funktion bei der Umsetzung des herrscherlichen Stiftungswillens hatte. Unter den Maitrakas agierte offenbar häufig der jeweilige Kronprinz (yuvarāja) als »Bote« (dūtaka). Das sollen einige Beispiele illustrieren: (1.) Am Ende der Herrschaft von Dharasena [II.], d.h. im späten 6. Jahrhundert, lautete der Name seines dūtaka "Śīlāditya«; und der Nachfolger dieses Königs war Śīāditya [I.]. (2.) In den letzten Regierungsjahren von Śīlāditya [I.] hieß dessen dūtaka »Kharagraha «; und diesem König folgte sein jüngerer Bruder Kharagraha [I.] auf den Thron. (3.) »Dharasena« lautete der Name des dūtaka von König Kharagraha [I.], und sein Nachfolger war sein Sohn Dharasena [III]. ${ }^{17}$ Ab Śīlāditya [III.] änderte sich die Situation: die dūtakaNamen lauteten weiterhin »Dhruvasena«, "Kharagraha«, »Dharasena«, doch alle Maitraka-Könige trugen nun den Namen »Śīlāditya «. Diese Beleglage könnte ein Indiz dafür sein, dass die späten Maitrakas erst bei der Krönung den Namen "Śīlāditya « annahmen.

Es stellt sich jedoch die Frage, warum gerade der Thronname "Śīlāditya « unter den Maitrakas so beliebt wurde. Sīlāditya [I.] (Urkunden aus den Jahren 605-611 n. Chr.) war Zeitgenosse des berühmten nordindischen Herrschers Harșa bzw. Harșavardhana von Kanauj (606-647 n. Chr.). Der Pilgermönch Xuanzang, der in der ersten Hälfte des 7. Jahrhunderts von China nach Indien reiste, nannte in seinem Bericht nicht nur Maitraka Śīāditya [I.], sondern auch König Harṣa »bei seinem laudativen Beinamen Śilāditya - >Sonne der Tugend $« .{ }^{18}$ Als der chinesische Pilger durch den Westen Indiens zog, regierte dort nach seiner Aussage bereits Dhruva[sena] [II.] (Urkunden aus den Jahren 629-642 n. Chr.), einer der Neffen von Maitraka Sīlāditya [I.], der mit einer Tochter von Harṣa verheiratet gewesen sein soll. ${ }^{19}$ In der zweiten Hälfte des 7. Jahrhunderts kehrte die Thron-

17 Ebd., 37. Jedoch nicht immer trat der als dūtaka fungierende Kronprinz auch tatsächlich die Thronfolge an.

18 René Grousset, Die Reise nach Westen oder wie Hsüan-tsang den Buddhismus nach China holte, übers. v. Peter Fischer/Renate Sснмidt, München 1986 (frz. Originalausg. Paris 1929), 177.

19 Grousset 1986, 250f.; Samuel BeAL, Si-Yu-Ki: Buddhist Records of the Western World. Translated from the Chinese of Hiuen Tsiang (Trübner's Oriental Series [45]), 2 Bde., London 1884, Bd. 2, 261 und 267; Samuel BeAL, The Life of Hiuen-Tsiang. By the Shaman Hwui Li, 
folge über Śīlāditya [II.], der wohl selbst nicht regiert zu haben scheint, wieder zur direkten Linie von Śìlāditya [I.] zurück. Der Thronname »Śīlāditya« könnte unter Śīāditya [III.] und seinem Nachfolger als bewusste legitimatorische Bezugnahme auf die direkte Abstammung von Maitraka Śìāditya [I.] eingesetzt worden sein. Eine indirekte Anspielung auf die Heiratsallianz mit Harṣa alias Sīlāditya von Kanauj wäre ebenfalls nicht auszuschließen. Diese matrimoniale Verbindung ist allerdings nur aus den Berichten des Xuanzang und seines Begleiters bekannt; sie wird in den Maitraka-Urkunden selbst nicht erwähnt. Überdies betraf sie - aus Perspektive der Abkömmlinge von Śīāditya [I.] - lediglich einen Seitenzweig des Maitraka-Herrscherhauses, d.h. den Sohn (Dhruvasena [II.]) und Enkel (Dharasena [IV.]) eines Bruder (Kharagraha [I.]) von Śīlāditya [I.]. ${ }^{20}$

Beinamen auf ${ }^{\circ} \bar{a}$ ditya, "Sonne«, hatten sich schon vor der Regierungszeit von Śīlāditya [III.] großer Beliebtheit erfreut: Sīlāditya [I.] wird auch als "Dharmāditya« beschrieben, als "Sonne von Recht und Gesetz (dharma)«. König Śīāditya [I.] war angeblich "einer, dessen zweiter Name (dvitīya-nāman) >Dharmāditya daher rührte, dass er nach Materiellem (artha), Glück und Wohlstand strebte, ohne den dharma dabei zu verletzen" (dharmānuparodhojjvalatarīkrtärthasukhasampadupasevānirū dhadharmādityadvitīyanāmāa). König Dhruvasena [II.] trug den Beinamen »Bālāditya«, »Morgensonne«. Über ihn heißt es unter anderem, dass "sein berühmter Zweitname `Bālāditya passend ist, da die Welt durchzogen sei von der Hingabe (wörtlich `Röte`) [seiner] Untertanen, die zum Zeitpunkt [seines sonnenartigen] Aufstiegs entstand ( (udayasamayasamupajanitajanatānurāgaparipihitabhuvanasamarthitaprathitabālädityadvitīyanāmā). König Kharagraha [II.] wird wiederum als "Dharmāditya « porträtiert, und zwar als jemand, der "markanter- und berechtigterweise den anderen Namen (aparanāman) ১Sonne des dharma< trug" (spaștam eva yathärtham dharmädityāpara$n \bar{a} m \bar{a}) .^{21}$

Ab Śīlāditya [III.], also seit der 2. Hälfte des 7. Jahrhunderts, wurden, wie bereits erwähnt, alle Maitraka-Herrscher in ihren (offiziellen) Urkunden »Śīlāditya" genannt, und es gibt auch keine Hinweise auf Sekundogenitur mehr. So folgten auf Śīlāditya [III.] dessen Sohn Śīlāditya [IV.], dessen Enkel Śīlāditya [V.], dessen Urenkel Śīlāditya [VI.] sowie dessen Ururenkel Śīāditya [VII.]. All

London 1911, 149. Zu den widersprüchlichen Angaben hinsichtlich dieser Heiratsallianz im Bericht des Xuanzang (BeAL 1884) und im Bericht seines Begleiters (BEAL 1911), siehe Hans T. BAKKER, The World of the Skandapurāna. Northern India in the Sixth and Seventh Centuries, Leiden/Boston 2014, 107, Anm. 319.

20 Auch Xuanzang nennt [Maitraka] Śilāditya [I.] als Onkel von Dhruva[sena] [II.]; vgl. BEAL 1884, Bd. 2, 267.

21 Die Übersetzungen stammen von der Autorin. $\mathrm{Zu}$ einem entsprechenden Urkundentext in Sanskrit vgl. z. B. Vajeshankar G. Ојна/Th. von SснтscherbatsкoI, Lunsadi Plates of Siladitya II.[sic!]; [Gupta-] Samvat 350, in: Epigraphia Indica 4 (1896/97), 76, Zeile 12; 78, 79, Zeile 47. 
diese Maitraka-Könige benutzten imperiale Titel und bezeichneten sich und ihre Vorfahren als parama-māheśvara, als "große Anhänger des [Gottes] Siva ${ }^{22}$

Diese epigraphisch-urkundliche Homogenisierung der Dynastiegeschichte der Maitrakas hatte aber bereits früher begonnen, am Beginn des 7. Jahrhunderts, unter dem König Śilāditya [I.]. ${ }^{23}$ Dieser Herrscher hatte die Genealogiebeschreibung neu fassen lassen. Nun wurde zwar noch der Dynastiegründer genannt, und zwar mit seinem sanskritisierten Namen "Bhațārka«, seine Söhne aber - deren Regentschaft einen klaren Beleg für fortgesetzte Sekundogenitur unter den frühen Maitrakas darstellte - wurden übergangen. Mit Ausnahme des Dynastiegründers Bhațārka ließ Śīlāditya [I.] all diejenigen Vorgänger tilgen, die sich nur als Heerführer oder Vasallenfürst, jedoch noch nicht als »Monarch» bezeichnet hatten. Außerdem ließ Sīlāditya [I.] - laut urkundlichem Befund selbst ein paramamāheśvara ${ }^{24}$ - nur noch solche Vorfahren aufführen, die sich ebenfalls als "Siva-Anhänger« betrachtet hatten.

Religiöse Epitheta, deren Gebrauch bei vielen mittelalterlichen indischen Dynastien üblich war, ${ }^{25}$ sind zwar keine echten Beinamen, stehen strukturell und funktional aber zwischen den Herrschertiteln und den Königsnamen. Unter den frühen Maitrakas ist das Bild gemischt: Nach urkundlichem Befund waren die ersten drei Könige "Anhänger des Gottes Śiva«. König Dhruvasena [I.] betrachtete sich als »Viṣnu-Anhänger ( paramabhāgavata); Dharapaț̣a, sein jüngerer Bruder, wird als »Verehrer des Sonnengottes« (paramādityabhakta) vorgestellt. Sein Sohn Guhasena nannte sich einmal sogar »[buddhistischer] Laienanhänger« (paramopāsaka). Das starke Streben nach Homogenisierung unter Sìlāditya [I.] führte schließlich dazu, dass sogar auf die Erwähnung seines eigenen Urgroßvaters Dharapața, eines paramādityabhakta, verzichtet wurde. Sein Großvater Guhasena ist zwar aufgeführt, aber als paramamāheśvara, als »Anhänger des Śiva «, nicht als Buddhist. ${ }^{26}$

Im Folgenden sollen nun die Königsnamen der Rāṣtrakūṭa-Dynastie betrachtet werden, wie sie in etwa 75 Kupfertafelurkunden aus dem 8. bis

22 Schmiedchen 2018, 37; Ojha/Schtscherbatskoi 1896/97, 76-80.

$23 \mathrm{Zu}$ diesen Vorgängen vgl. Schmiedchen 2018, $39 \mathrm{f}$.

24 Interessanterweise behauptet der chinesische Pilgermönch Xuanzang, Maitraka Sīlāditya [I.] habe - ebenso wie Harșa von Kanauj und Maitraka Dhruvasena [II.], die sich in ihren Urkunden jeweils als paramamāheśvara bezeichneten - dem Buddhismus nahegestanden; vgl. BEAL 1884, Bd. 1, 213 f.; Bd. 2, 261 und 267.

25 Vgl. hierzu Annette Schmiedchen, Religious Patronage and Political Power: The Ambivalent Character of Royal Donations in Sanskrit Epigraphy, in: Journal of Ancient Indian History 27 (2010/11), 154-166.

26 Schmiedchen 2018, $39 \mathrm{f}$. 
10. Jahrhundert überliefert sind. ${ }^{27}$ In den Rāșțrakūṭa-Inschriften sind nur die Herrschertitulaturen in Prosa, die Genealogien jedoch in Versen abgefasst. Eine wichtige legitimatorische Funktion kam auch bei diesem Königshaus den von den Herrschern benutzten Titeln (d.h. Statusbezeichnungen) und Epitheta (Beioder Schmucknamen) zu. Um die Mitte des 8. Jahrhunderts hatten die Rāștrakūṭas in Maharashtra die Dynastie der frühen Westlichen Calukyas abgelöst. ${ }^{28}$ Mit der Machtübernahme legte sich die Rāșțrakūṭa-Hauptlinie eine imperiale Titulatur zu. Sie bestand aus den in Indien seit dem späten Altertum, seit der Gupta-Zeit (4.-6. Jahrhundert), überregional benutzten imperialen Titeln mahārājādhirāja, "Oberkönig der Großkönige«, parameśvara, „Oberherrscher«, und parama-bhatțāraka »höchster Gebieter«. Zudem übernahmen die Rāștrakūtas den von ihren Vorgängern eingeführten offiziellen Titel prthivī-valla$b h a$, "Liebling der Erde «. ${ }^{29}$ Dies weist darauf hin, dass sie sich als legitime Erben des Calukya-Reiches betrachteten. Aus der Wahl dieses Titels geht hervor, welche Bedeutung die Rāṣțrakūṭas dem endgültigen militärischen Erfolg über die frühen Westlichen Calukyas für ihren Anspruch auf imperiale Hegemonie über den gesamten Subkontinent zumaßen. ${ }^{30}$

Auch bei den Rāṣtrakūṭas sind die Prosatitulaturen in den Stiftungspassagen ihrer offiziellen Urkunden hinsichtlich der Namensgebung aufschlussreich. Mitunter wird explizit erwähnt, dass die Rāṣțrakūṭas neben Haupt- (mukhyanāman) auch Beinamen (gauna-nāman) trugen. ${ }^{31}$ Sanskritnamen wie "Indra", »Karka«, »Kṛṣna«, »Govinda«, »Dantidurga» und auch »Dhruva» wurden offenbar bei Geburt an männliche Angehörige der Dynastie vergeben.

Anlässlich der Übernahme der Regentschaft scheinen - wie bei anderen mittelalterlichen indischen Herrscherhäusern - diverse Beinamen hinzugekommen zu sein. Dabei setzten die Rāṣṭrakūṭa-Könige wohl zur selbstdefinitorischen Abgrenzung spezifische Akzente, indem sie sich bewusst gegen Bildungen entschieden, die schon bei anderen zeitgenössischen indischen Königsdynastien verbreitet waren. Diverse südindische Dynastien (die Pallavas, Kadambas und Westlichen Gangas) benutzten zum Beispiel Namen auf ${ }^{\circ}$ varman. ${ }^{32}$ Das zweite Glied der so konstruierten Namenskomposita bedeutet "Schutzwehr; [Brust-]Panzer« und diente zur Bildung klassischer Namen für den sogenannten

27 Vgl. hierzu Annette Schmiedchen, Herrschergenealogie und religiöses Patronat: Die Inschriftenkultur der Rāsțrakūṭas, Śilāhāras und Yādavas (8. bis 13. Jahrhundert) (Gonda Indological Studies 17), Leiden 2014, 460-485.

28 Ebd., 7.

29 Ebd., 62.

30 Ebd., 441.

31 Ebd., 39 und Anm. 35.

32 Einzige Ausnahme in dieser Hinsicht ist der Name "Dantivarman«; vgl. ScHMiedCHEN 2014, 39, Anm. 36. 
kṣatriya-Stand, ${ }^{33}$ d.h. Angehörige des Adels. Sehr typisch für die Rāṣțrakūṭas waren Komposita auf ${ }^{\circ}$ varșa (»Regen, regnend») und ${ }^{\circ}$ tunga (»Gipfel«), die fast ebenso eindeutig wie der Name des Herrschergeschlechts die dynastische Identität markierten. Besonderer Beliebtheit erfreuten sich vor allem die Epitheta auf ${ }^{\circ}$ varșa, die auf die Freigebigkeit der Rāșțrakūṭas und auf die herrscherliche Kraft als >Regenmacher`sowie auf die maskuline Potenz ihrer Könige anspielten. ${ }^{34}$ Die von den / für die Rāṣțrakūṭas offenbar ıerfundenen`varșa-Namen wurden später von anderen Königen übernommen. ${ }^{35}$

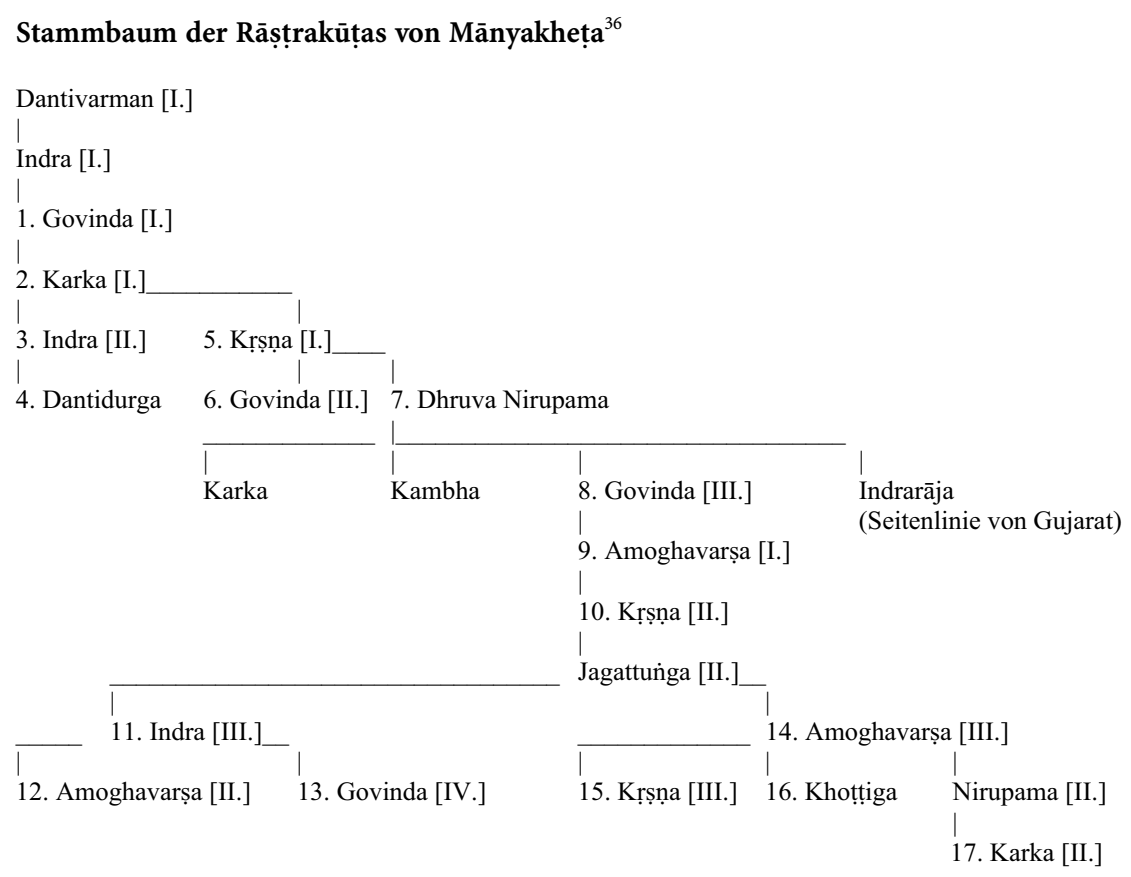

Bei der Zuordnung von Epitheta gab es unter den Rāșțrakūṭas deutliche Ansätze zu festen Namenskombinationen, die unter legitimatorischen Aspekten ein wichtiges Kennzeichen für dynastische Kontinuität darstellten. Drei Regenten

33 Sснмітт 1995, 648.

$34 \mathrm{Zu}$ dem letztgenannten Aspekt vgl. Duncan M. Derrett, Bhü-bharaṇa, bhū-pālana, bhūbhojana. An Indian Conundrum, in: Bulletin of the School of Oriental and African Studies 22,1 (1959), 108-123.

35 John F. FleEt, Some Records of the Rashtrakuta Kings of Malkhed: The appellations of the Rāshṭrakūṭas of Mālkheḍ, in: Epigraphia Indica 6 (1900/01b), 188, Anm. 5.

36 Die Urkunden selbst enthalten keine Nummerierung der Könige; diese ist - wie bei den Maitrakas - sekundär. 
der Haupt- und zwei der Seitenlinie hießen »Kṛṣna Akālavarṣa [Śubhatunga] «. ${ }^{37}$ Mit »Dhruva « wurden die Beinamen »Dhārāvarșa « und »Nirupama «; ${ }^{38}$ mit »Karka» dann "Suvarṇavarṣa « kombiniert. ${ }^{39}$ König Indra [III.] nannte man »Nityavarșa Vikramatunga ${ }^{40}{ }^{20}$ Lediglich bei den Rāșțrakūṭas, die "Govinda « hießen, ist die Verwendung nicht konsistent. Ab Govinda [II.] trugen sie den Beinamen »Prabhūtavarșa $;_{;}^{41}$ Govinda [IV.] nannte sich zusätzlich noch »Suvarṇavarṣa«. Bei Govinda [II.] und Govinda [III.] variierte der Gebrauch der ${ }^{\circ}$ tunga-Epitheta: ersterer wurde als »Prabhutunga», letzterer als »Jagattunga bezeichnet. $^{42}$ Der Sohn von Govinda [III.] hieß »Amoghavarṣa Mahārājaśarva Nṛpatunga «. ${ }^{43}$ Amoghavarṣa [II.] und Amoghavarșa [III.] sind nur unter diesem (Bei-)Namen bekannt, Amoghavarșa [IV.] hieß »Karka Nṛpatunga».

Eine Mittelstellung zwischen diesen persönlichen Beinamen und den Herrschertiteln nahmen Bildungen auf ${ }^{\circ}$ vallabha ein. Dantidurga führte bereits, als er noch Vasallenfürst der frühen Westlichen Calukyas war, den von diesen vergebenen / übernommenen Titel prthivivvallabha, "Liebling der Erde«, in seiner Prosatitulatur. Das Bildungselement ${ }^{\circ}$ vallabha ließen einige Rāṣtrakūta-Könige aber auch für zusätzliche spezifische Beinamen einsetzen. So wurde Dhruva unter anderem »Kalivallabha " genannt, ${ }^{44}$ und Amoghavașa [I.] trug den Beinamen »Tribhuvanavallabha», "Liebling der drei Welten«, bzw. "Śrīvallabha», »Liebling des Glücks«.

Die Kenntnis der onomastischen Praxis unter den Rāșțrakūṭas speist sich in erster Linie aus deren Titulaturen, in denen die Epitheta dem jeweiligen Hauptnamen wie Titel vorangestellt wurden. Häufig bestätigen die metrischen Genealogien, für die verschiedene Vorlagen benutzt wurden, ${ }^{45}$ die Angaben der Prosatitulaturen. In diesen Dynastiebeschreibungen findet sich nur selten mehr als ein Beiname pro Strophe. In der Frühzeit war es üblich, das genealogische

37 Vgl. hierzu Schmiedchen 2014, 40. »Akālavarșa» bedeutet »zur Unzeit regnend» und steht für jemanden, der es auch außerhalb der Regenzeit »regnen lässt«; "Śubhatunga « lässt sich übersetzen mit »Glanzgipfel«.

38 "Dhārāvarṣa « bedeutet »in Strömen regnend; Regenguss«; "Nirupama« bedeutet »der Unvergleichliche".

39 »Suvarṇavarșa» bedeutet »Goldregen«.

40 »Nityavarșa $=$ = «tetig regnend «, in ähnlichem Sinne wie »Akālavarșa«; »Vikramatunga» lässt sich übersetzen mit »Kraftgipfel« und ist auch als Königsname im `Kathāsaritsāgara belegt; vgl. Monier-Wiliams 1899, 955.

41 »Prabhūtavarșa» bedeutet »reichlich regnend».

42 »Prabhutunga « bedeutet »Gipfel der Fürsten«; »Jagattunga« bedeutet »Gipfel der Welt«.

43 "Amoghavarșa" bedeutet "fruchtbringender Regen" und "Nrpatunga» "Gipfel der Herrscher «. »Mahārājaśarva» bedeutet wohl "Śarva (= Śiva) unter den Großkönigen«; vgl. hierzu SCHMiedChen 2014, 40, Anm. 41.

44 »Kalivallabha« bedeutet "Liebling des Kali-Zeitalters«; zu diesem Beinamen siehe weiter unten, Anm. 52.

45 Zur Klassifizierung dieser Vorlagen durch Nummerierung vgl. Schмiedchen 2014, $20 \mathrm{f}$. 
Gerüst anhand der Hauptnamen zu entwickeln. ${ }^{46}$ Zusätzliche Strophen konnten dazu dienen, diverse Beinamen zu erklären. Namensreihungen waren in den Prosatitulaturen häufiger als in den metrischen Genealogien, doch schon unter Krṣṇa [I.] zeichnete sich die Tendenz ab, den ${ }^{\circ}$ varșa-Namen den Vorzug zu geben. Das führte dazu, dass in späteren Darstellungen für die Vorfahren nicht mehr ausschließlich der jeweilige Haupt-, sondern häufig nur ein Beiname überliefert wurde. So stellte die Genealogievorlage $>3$ « zwar noch Karka [I.], Indra [II.] und Dantidurga unter ihren Hauptnamen vor, setzte die Aufzählung der darauf folgenden Könige aber dann mit Akālavarṣa (= Kṛṣna [I.]), Prabhūtavarṣa (= Govinda [II.]), Dhārāvarṣa (= Dhruva), Prabhūtavarṣa Jagattunga (= Govinda [III.]) und Amoghavarṣa [I.] fort. ${ }^{47}$

In den jüngeren Fassungen blieb es nicht bei der einseitigen Präferenz für ${ }^{\circ}$ varṣa-Bildungen. Vielmehr scheint sich die Praxis durchgesetzt zu haben, aus einzelnen Namensreihen immer ein ganz bestimmtes Epitheton auszuwählen, wobei auch so die Wiederholung bestimmter Haupt- und Beinamen nicht ganz vermieden werden konnte. Während in den Vorlagen $>4$ « bis $>8$ « Kṛ̣na [I.] und Govinda [II.] unter diesen Namen behandelt wurden, waren für Dhruva die Bezeichnung "Nirupama«, für Govinda [III.] die Benennung "Jagattunga» und für dessen Sohn der Name "Amoghavarșa» am gebräuchlichsten. Die Verwendung dieser Beinamen führte dazu, dass einige weniger prominente Dynasten nur unter ihren Beinamen bekannt wurden (z. B. Jagattunga [II.] und Nirupama [II.], die weder regiert noch eigene Urkunden hinterlassen haben). ${ }^{48}$

In den bisherigen Ausführungen wurde der Begriff `Namensgebung « nicht nur in der engeren Bedeutung des in den `Gṛhyasūtras` beschriebenen nāmakaraṇa, sondern in einem erweiterten Sinne benutzt. Inwiefern die für (männliche) Mitglieder der Rāșțrakūṭa-Dynastie belegten Namen und Beinamen den von den Eltern im Rahmen von nāmakaraṇa-Ritualen vergebenen Geburtsnamen entsprachen, die z.T. geheim waren und erst bei einer upanayana-Zeremonie bekanntgegeben wurden, ist nicht klar. ${ }^{49}$

Es ist ebenfalls nicht sicher, ob es im 8./9. Jahrhundert unter den Rāṣţrakūṭas bereits ausgesprochene Krönungsnamen gab, die mit der Herrschertitulatur angenommen wurden. Die Tatsache, dass Bildungen auf ${ }^{\circ}$ varșa und ${ }^{\circ}$ tunga auch für Mitglieder der Hauptlinie, die nie regiert haben, für Kronprinzen, für Fürsten der Seitenlinie und für andere Rāșțrakūṭa-Prinzen verwendet wurden, ${ }^{50}$ spricht eher dagegen oder zumindest für eine nicht stringente Praxis. Den Charakter von

46 Ebd., 41.

47 Ebd., 41.

48 Ebd., 41.

49 Ebd., 44.

50 Ebd., 44, Anm. 49. 
selbstgewählten Herrschernamen hatten eventuell die im 10. Jahrhundert eingeführten religiös konnotierten Beinamen, auf die noch einzugehen sein wird.

Zunächst aber sollen einige konkrete Beispiele für die `Interpretation` der Epitheta betrachtet werden: Die Eulogie von Kṛnna [I.], dessen kompletter Name »Kṛṣna Akālavarṣa Śubhatunga» lautete, enthält Anspielungen auf dessen Beinamen und entwirft das Bild eines in jeder Hinsicht idealen Herrschers, wozu neben der Beschreibung seiner Freigebigkeit, Bündnistreue und militärischen Potenz gehört, dass er als großartiger Liebhaber charakterisiert wird:

viṣameṣu viṣamaśīlo yas tyāgamahānidhir daridreṣu /

kāntāsu vallabhatarah khyātah praṇateșu śubhatungah //1.22A//

»Er ist berühmt als einer von grimmigem Charakter gegenüber den Grimmigen, als ein Hort der Freigebigkeit gegenüber den Armen, als ein großer Liebhaber (vallabha-tara) gegenüber den Geliebten [und] als ein `Glanzgipfel` (śubha-tunga) gegenüber den Untertanen [1.22A]."

suhṛdi dhanaṃ ripuṣu śarāṃ yuvatijane kāmam aśaraṇe śaraṇaṃ I

yah santatam abhivarșann akālavarșo bhuvi khyātah //1.23A//

"Er ist in der Welt bekannt als reiner, der es [auch] zur Unzeit (= zu jeder beliebigen Zeit) regnen lässt` ( $a k a \bar{l}$ a-varșa), der auf den Freund Reichtum, auf die Feinde Pfeile, auf die Jungfrauen Liebe, auf den Schutzlosen Schutz stets herabregnen lässt [1.23A]. ${ }^{51}$

König Dhruva, dessen voller Name "Dhruva Dhārāvarṣa Nirupama Kalivalla-

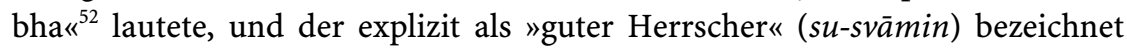
wird, attestierte man nicht nur Freigebigkeit und Heldenmut, Rechts- und Wahrheitstreue, sondern behauptete auch, dass er »die Erde bis zur Meeresküste regiert", also den ganzen Subkontinent beherrscht habe. ${ }^{53}$ Deutlicher als für Kṛșna [I.] wird für Dhruva postuliert, er habe das `schlechte Zeitalter ‘ außer Kraft gesetzt und die Verhältnisse eines 'goldenen Zeitalters` (krta-yuga) hergestellt:

labdhapratiștham acirāya kaliṃ sudūram

utsārya śuddhacaritair dharanītalasya /

kṛtvā punah kṛtayugaśriyam apy aśeșaṃ

citraṃ katham nirupamaḥ kalivallabho [']bhūt //2.9//

"Wie wunderbar ist es, dass Nirupama (= Dhruva) ein Kalivallabha wurde, nachdem er das auf der Erde etablierte Kali[yuga] schnell durch [seinen] reinen Lebenswandel sehr weit weg geschafft und auch das Glück des Kṛtayuga völlig wiederhergestellt hatte $[2.9] . \varkappa^{54}$

51 Ebd., 67.

$52 \mathrm{Zu}$ dem letztgenannten, eher ungewöhnlichen Epitheton vgl. John F. FLEET, Nilgund Inscription of the Time of Amoghavarsha I.; A. D. 866, in: Epigraphia Indica 6 (1900/01a), 105, Anm. 9.

53 Schmiedchen 2014, 73, Strophe 1.31.

54 Ebd., 76, Strophe 2.9. 
Nach den geläufigsten indischen Theorien von den vier Weltzeitaltern regierten bereits die Rāșțrakūṭas im `schlechten Zeitalter` (kali-yuga); aber auch wir leben heute noch in diesem Zeitalter, das im Jahr 3102 v. Chr. begann. ${ }^{55}$

Am Beginn des 10. Jahrhunderts kam es zu einer markanten Neuerung bei der Rāṣṭrakūṭa-Hauptlinie: König Indra [III.] führte mit seiner Thronbesteigung im Śaka-Jahr 836 (914/915 n. Chr.) eine ganze Reihe von religiös konnotierten Epitheta und schmückenden Beinamen ein. Mitunter wurden diese in abgewandelter Form auch noch von seinen Nachfolgern benutzten Epitheta, die auf ${ }^{\circ}$ kandarpa, ${ }^{\circ}$ caturmukha, ${ }^{\circ}$ trinetra, ${ }^{\circ}$ nārāyaṇa bzw. ${ }^{\circ}$ märtaṇda lauteten und Bezüge zum Liebesgott Kāma, zu den Göttern Brahman, Śiva und Viṣnu und zum Sonnengott Sūrya implizierten, wie ältere Beinamen in den Genealogiestrophen diskutiert. Systematisch wurden sie aber, um den Rahmen der Titulatur nicht zu sprengen, in einem der Titelreihung vorgeschalteten, separaten Prosapassus aufgeführt und erklärt:

Spezielle Prosareihen von Beinamen für Indra [III.], Govinda [IV.] und Karka [II.]

Indra [III.] Kīrtinārāyaṇa Raț̣akandarpa Rājamārtaṇḍa Vijayāvaloka (RāUr 60) ${ }^{56}$ Geyacaturmukha Kīrtinārāyaṇa Manujatrinetra Rājamārtạ̣̣̣a Rațakandarpa Vikramatunga (RāUr 63-64)

Govinda [IV.] Nityakandarpa Cāṇakyacaturmukha Vikrāntanārāyaṇa Nṛpatitrinetra (RāUr 67)

Karka [II.] Nūtanapārtha Ahitamārtaṇ̣̣a Vīranārāyaṇa Nṛpatunga Rājatrinetra $(\text { RāUr 75) })^{57}$

Indra [III.] war der erste Rāṣțrakūṭa-Herrscher, der gleich zu Beginn seiner Regierungszeit die Stammbaumdarstellung für sich und seine Vorfahren neu schreiben ließ. Die metrischen Genealogievorlagen $>4$ « und $>5 \iota$, die bereits seit dem Tage seiner Thronbesteigung verwendet wurden, ${ }^{58}$ enthalten ausführliche Erläuterungen zu seinen verschiedenen Namen. In RāUr 60 fasst die Prosapassage, die sich an Strophen der Vorlage $>4$ « anschließt, die entsprechenden metrischen Ausführungen noch einmal zusammen:

yaś ca sakalajalanidhivelāvanāntararamamāṇakinnarakimpuruṣakāntakāminīkīrttyamānakīrttanīyakīrttị kīrttinārāyaṇo nijanirupamarūpasaundaryyanirjjitakamanīyakanndarpparūpadarpporațtakandarppah / sakaladurddharariputimirapatalapātanapațupratāpaprasareṇa virājamāno rājamārttaṇ̂́ caṇ̣̂adorddaṇdmaṇdala-

55 Vgl. z. B. Axel Michaels, Der Hinduismus. Geschichte und Gegenwart, München 1998, 331; Fred Virkus, Die Könige und das verdorbene Zeitalter - politische Propaganda und Weltzeitaltertheorie im frühmittelalterlichen Indien, in: Das Altertum 42 (1997), 207-212.

$56 \mathrm{Zu}$ den Inventarnummern der Rāștrakūṭa-Kupfertafelurkunden (RāUr) vgl. SCHMiedCHeN 2014, 10, Anm. 10.

57 Ebd., 44. Zur Bedeutung der einzelnen Beinamen siehe weiter unten.

58 Genealogievorlage `5 scheint ausschließlich für Stiftungen an jinistische Empfänger benutzt worden zu sein; vgl. ebd., 37. 
viśrā[nta]vijayaśrīr vvijayāvalokah sphuradārūḍavajrapāṇir vvividhavibudhajanāśrayañìyaśrịh śrimmadindrarājadeva ityanekavidhadhanyanāmadheyaḥ samabhavat I

"Und dieser wurde jemand, der viele verschiedene glückverheißende Namen besitzt: [1.] `Kīrti-nārāyaṇa` (`Ruhmes-Viṣnu〈), weil sein zu feiernder Ruhm von allen Kinnaras und Kimpurușas ${ }^{59}$ Liebhabern und Geliebten erwähnt wird, die sich in den Wäldern an den Ufern der Meere vergnügen; [2.] >Rațța-kandarpa` ( (Liebesgott der Rāṣțakūṭas`), ${ }^{60}$ weil der Neid auf die Gestalt des entzückenden Liebesgottes durch die eigene, unvergleichliche körperliche Schönheit besiegt ist; [3.] >Rāja-mārtaṇḍa`(১Sonnengott der Könige `), weil er durch ein Übermaß an hellem Glanz herrscht, der den Schleier der Finsternis, [d.h.] alle schwer zu bezwingenden Feinde, zerstört; [4.] /Vijayāvaloka ( (Ebenbild des Sieges $`$ ), da er die Siegesgöttin in den Gebieten [seines Reiches] durch seine starken Arme zur Ruhe gebracht hat [und] [5.] redler Indrarājadeva‘, weil in seine Hand ein blitzender Donnerkeil gelangt ist und [seine] Macht verschiedensten weisen Leuten Zuflucht bietet. ${ }^{61}$

Ein ähnlicher Abschnitt für König Indra [III.] findet sich auch in RāUr 63 (und RāUr 64) im Anschluss an die auf Vorlage $>5$ « beruhende metrische Beschreibung des Stammbaumes der Rāṣțrakūṭa-Dynastie:

yaś ca vinayavinatānekabhūpālamaulimālālālitacaraṇāravindayugalaḥ saundaryyaśauryyacāturyyaudāryyadhairyyagāmbhīryyavīryyādibhir akhilajanāś caryyakāribhir ahitabahunrpaiśvaryyahāribhir mmahāgunair upārjitānavadyavidyotamānavividhanāmadheyah svarājyalīlāvinirjitaśatamakhah śrīgeyacaturmukhah godānabhūmidānakanakadānādyanekānūnadānaparāyaṇaḥ śrīkīrtinārāyaṇaḥ saṃtrāsitodvrttaśatruvarapurolāsitasitātapattrah śrīmanujatrinetrah / svakīyodayavikāsitāśsṣavinatajanavadanapundarīkaṣandạ śrīrājamārtandạ samutkhātasubhagamāninīmahābhimānasaubhāgyadarppaḥ śrīrațtakandarppạ̣ parākramākrāntasamastapārthivottungah śrivikramatungah samabhavat /

»Und dieser, dessen Fußlotuspaar liebkost wird vom Kopfschmuck vieler Könige, die sich seiner Kontrolle beugen, erlangte verschiedene makellose und glänzende Namen durch große Tugenden, die alle Leute in Staunen versetzen und die Herrschaft vieler feindlicher Könige rauben, wie Schönheit, Mut, Geschick, Freigebigkeit, Festigkeit, Tiefe, Kraft usw.: [1.] `Śrī-Geya-caturmukha` (`edler zu preisender Brahman`), weil er Śatamakha (= Indra) übertrifft durch sein Herrschaftsspiel; [2.] 'Śrī-Kīrti-nārāyaṇa (`edler Ruhmes-Viṣnu), weil er sich dem vielfältigen und umfangreichen Geben von Kühen, Land, Gold etc. widmet; [3.] ১Śrī-Manuja-trinetraく (১edler Śiva unter den Men-

59 Dies sind zwei häufig gemeinsam genannte Gruppen von mythischen Mischwesen, zur Hälfte Mensch, zur Hälfte Tier; vgl. Monier-Wiliams 1899, $282 \mathrm{f}$.

60 Zur Beziehung zwischen der Prakrit-Namensform »Rața» und der Sanskrit-Namensform »Rāsțrakūta» vgl. John F. FLEET, Some Records of the Rashtrakuta Kings of Malkhed: The family-name of the Rāshṭrakūṭas of Mālkhẹ,, in: Epigraphia Indica 7 (1902/03), 214-223. Zur Benutzung der beiden Namensformen in den Inschriften dieser Dynastie vgl. SCHMIEDCHEN 2014, 49-53.

61 Ebd., 104. Der letzte Vergleich spielt darauf an, dass dieser Rāștrakūṭa-König den Namen des Götterkönigs Indra trug, der bereits in vedischer Zeit als Gewittergott verehrt wurde. 
schen`), weil er seinen weißen Schirm über den besten Städten der zitternden, stolzen Feinde leuchten lässt; [4.] ১Śrī-Rāja-mārtaṇḍa ( ‘edler Sonnengott der Könige`), weil die `Gesichtslotusse` der sich [ihm] unterwerfenden Leute erblühen durch seinen Aufstieg; [5.] `Śrī-Rațta-kandarpa` (`edler Liebesgott der Rāștrakūṭas`), weil Hochmut und Eitelkeit der auf ihre Schönheit eingebildeten Frauen von ihm ruiniert werden; [6.] `ŚrīVikrama-tunga` (`edler Gipfel der Kraft $\iota$ ), weil er alle Könige überragt, indem er sie durch Kraft bezwingt. ${ }^{62}$

Demnach wurden unter Indra [III.], dessen Beiname `Nityavarșaı nur in der Prosatitulatur Verwendung fand, die Epithetareihen erheblich erweitert und quasi systematisch erfasst und erklärt. Mit dem viṣnuitischen Beinamen »Kīrtinārāyaṇa", "Ruhmes-Viṣṇu«, hatte schon Amoghavarșa [I.], der sich selbst "Vīra-nārāyaṇa«, "Helden-Viṣnuu, nannte (Strophen 3.47, 4.13), seinen Vater Govinda [III.] (Strophe 3.23) bezeichnet. Das Epitheton »Rāja-mārtaṇ̣a«, "Sonnengott der Könige«, erscheint zum ersten Mal im Zusammenhang mit Indra [III.], geht aber wohl auf den von Amoghavarșa [I.] gebrauchten Beinamen "Raț̣a-mārtaṇḍa«, »Sonnengott der Rāṣțrakūṭas«, zurück (3.41), ${ }^{63}$ der seinerseits wiederum die Bildung des Epithetons »Rațta-kandarpa«, "Liebesgott der Rāșțrakūṭas«, für Indra [III.] inspiriert haben dürfte. In einigen Urkunden wird die Titelreihe durch die Beinamen »Manuja-trinetra«, "Śiva unter den Menschen«, und »Geya-caturmukha«, »zu preisender Brahman«, vervollständigt.

Govinda [IV.] übernahm von seinem Vater Indra [III.], die Tradition, den Strophen der Genealogie eine Aufzählung und Erläuterung seiner Beinamen in Prosa folgen $\mathrm{zu}$ lassen:

yaś ca samupahasitaharanayanadahanavihitānityakandarpparūpasaundaryyadarppạ̣ śrīnityakandarppaḥ prabhumantraśaktyupabṛ̣hitotsāhaśaktisamākșiptaśatamakhasukhaś cāṇakyacaturmmukhah prathitaikavikramākrāntavasundharāhitakaraṇaparāyaṇaḥ śrīvikrāntanārāyaṇah svakarakalitahetihaladalitavipakșavakṣaḥsthalakṣetrah śrīnrpatitrinetrah samabhavat /

»Und er (= Govinda [IV.]), der den Stolz des Liebesgottes (Kandarpa) auf [seine] körperliche Schönheit verlacht, die sich als vergänglich (anitya) erwiesen hat durch das Feuer aus dem Auge des Hara (= Śiva) ${ }^{64}$ wurde [1.] ein `Śrī-Nitya-kandarpa (sedler beständiger Liebesgott`); er, der das Glück des Śatamakha (= Indra) vernichtet hat durch die Stärke seines Elans, welcher gesteigert worden ist durch die Kraft des Herrschers und [guter] Beratung, wurde [2.] ein >Cānakya-caturmukha` (`Schöpfergott unter den Cānakyas $)^{65}$; er, dessen Hauptanliegen Wohltaten für die Welt sind, die

62 Ebd., 105.

63 Ebd., 105.

64 Hier wird darauf angespielt, dass nach der indischen Mythologie Gott Śiva alias »Trinetra» (»Dreiauge, der Dreiäugige«) mit seinem dritten Auge den Liebesgott Kāma alias »Kandarpa» zerstört hat; vgl. MichaELS 1998, 241.

65 Hier wird darauf angespielt, dass Teile der indischen Tradition einen Mann namens Cānakya, Minister des Maurya-Königs Candragupta (4./3. Jh. v.Chr.), für den Autor eines Staats- 
erobert worden ist durch [seine] vorherrschende, einzigartige Macht, wurde [3.] ein 'Śrī-Vikrānta-nārāyaṇaı (`edler tapferer Viṣnuı); er, der die Brust [seiner] Feinde durchfurcht hat mit den in seinen Händen befindlichen Waffen - wie Felder mit einem Pflug - , wurde [4.] ein `Śrī-Nrpati-trinetra` (১edler Śiva unter den Herrschern`). « ${ }^{66}$

In der sich an die Epithetareihung anschließenden Titulatur von Govinda [IV.] ist dieser als "Suvarṇavarșa« bezeichnet. Das Verhältnis dieses Beinamens zu dem sonst mit dem Namen »Govinda « kombinierten Epitheton »Prabhūtavarṣa « wird in einer Strophe thematisiert:

\section{varṣan suvarṇnavarṣah prabhūtavarṣo pi kanakadhārābhị I \\ jagad akhilam ekakāmcanamayam akarod iti janair uktah //6.23//}

»Obwohl er ein `Prabhūta-varșa` (১reichlicher Regner`) ist, wird er von den Leuten `Suvarṇa-varșa (`Goldregner`) genannt, weil er, indem er Goldschauer regnen ließ, die ganze Welt zu einer nur aus Gold bestehenden machte. [6.23] « ${ }^{67}$

Bei Karka [II.] alias Amoghavarṣa [IV.] findet sich in RāUr 75 im Anschluß an die metrische Genealogie eine Prosa-Eulogie auf diesen Rāṣțrakūṭa-König, die den parallelen Passagen in den Urkunden von Indra [III.] sowie Govinda [IV.] ähnelt und die Beinamen von Karka [II.] erläutert:

yaś cānuparatakanakadhārānipātopajanitalokaharșaḥ śrīmadamoghavarṣah / svakauśalakșiptaniśitaśaravidāritārātisārthah śrīnūtanapārthah / sakalabalavadaritimirabhedanapracandah śrimadahitamārttandah / svavikramacchalitabalibandhaparāyanah śrīvīranārāyaṇah / sakalādirājacaritātiśayatungah śrīmannṛatungah / nikhilabhuvanādhipatyaprakāśitaikātapattrah śrīrājatrinettrah // samabhavat sadarthābhidhānatayā //

»Und dieser wurde durch adäquate Benennung: [1.] ein `edler Amoghavarșa‘, da er Freude bei den Menschen durch unaufhörliche Regenschauer von Gold erzeugt hat; [2.] ein `Śrī-Nūtana-pārtha` (`edler neuer Arjuna $)^{68}$, da er die Feindesscharen durch die scharfen Pfeile gespalten hat, die er mit der ihm eigenen Geschicklichkeit abschoss; [3.] ein `Śrīmad-Ahita-mārtaṇ̣̂a (`edler Sonnengott für die Gegner`), weil er erbarmungslos ist beim Auflösen der Finsternis (= beim Zerstören) aller mächtigen Feinde; [4.] ein `Śrī-Vīra-nārāyaṇa ( (edler Viṣnu unter den Helden`), weil [sein] höchstes Ziel in der Gefangennahme der Mächtigen besteht, die er ausmanövriert hat durch seine Kraft; [5.] ein `Śrīman-Nrpa-tunga` (`edler Gipfel unter den Herrschern`), weil er im Verhalten alle frühen Könige bei weitem übertrifft [und] [6.] ein ıŚrī-Rāja-trinetra

rechtslehrbuchs, des `Kauțilīya-Arthaśāstra` (Endredaktion 2./3. Jh. n.Chr.), halten. Der Name »Cāṇakya« taucht jedoch im überlieferten Text nicht auf. Nach Patrick Olivelle ist der Mythos einer Identität von Cāṇakya und Kauțilya erst in der Gupta-Zeit (4.-6. Jh. n. Chr.) entstanden; vgl. Patrick Olivelle, King, Governance, and Law: Kauṭilya’s Arthaśāstra. A New Annotated Translation, Oxford/New York 2013, 31-38.

66 SChMiedChen 2014, $111 \mathrm{f}$.

67 Ebd., 112.

68 "Pārtha« ist ein Beiname des Arjuna, eines Helden aus dem Epos `Mahābhārataর. 
(`edler Śiva unter den Königen`), weil [sein] ein[er] Schirm die Oberherrschaft über die ganze Welt illustriert. ${ }^{69}$

\section{Schluss}

Die untersuchten Beispiele der Maitraka- und Rāṣțrakūṭa-Dynastie dürften als Belege dafür gelten, dass im frühmittelalterlichen Zentralindien Königsnamen als Legitimationsinstrument zwecks Machterhalt und Herrschaftssicherung benutzt wurden. Bei den Maitrakas zeigten sich ab dem 7. Jahrhundert Anzeichen für die Verwendung eines Krönungsnamens, zumindest aber deutliche Tendenzen zur Homogenisierung der Königsnamen und religiösen Epitheta, die wohl in überzeichneter Form auf ausgeprägte dynastische Kontinuität hindeuten sollten. Unter den Rāṣțrakūṭas ist noch klarer, dass die Königsnamen als Legitimationsinstrument benutzt wurden. Beinamen und Epitheta waren mit dem Ideal des indischen Herrschers verbunden. Die dynastiespezifischen Beinamen auf ${ }^{\circ}$ varșa stellten einen idealtypischen Bezug zu der Freigebigkeit eines Herrschers her. Die unter den Rāṣțrakūṭas im 10. Jahrhundert eingeführten religiös konnotierten Beinamen belegen das Bestreben einer dynastischen Anbindung an die Welt der Götter: zur Legitimierung zwecks Machterhalt und Herrschaftssicherung. Diese Bezüge gehen über das Bekenntnis zu bestimmten Göttern weit hinaus; hierbei könnte es sich um Krönungsnamen gehandelt haben. Für beide Dynastien ließ sich jedoch zeigen, dass die Strategien zur Verwendung von Krönungsnamen jeweils einige Zeit reifen mussten, bis sie eingesetzt wurden: Die Maitrakas gingen erst im 7. Jahrhundert dazu über, ihren gekrönten Häuptern den Thronnamen »Śīlāditya« zu geben; und die Rāṣṭrakūṭas verwendeten wohl nicht vor dem 10. Jahrhundert religiöse Epitheta als Krönungsnamen.

\section{Literaturverzeichnis}

Hans T. BAKker, The World of the Skandapurāna. Northern India in the Sixth and Seventh Centuries, Leiden/Boston 2014.

Samuel Beal, Si-Yu-Ki: Buddhist Records of the Western World. Translated from the Chinese of Hiuen Tsiang (Trübner's Oriental Series [45]), 2 Bde., London 1884.

Samuel BeAL, The Life of Hiuen-Tsiang. By the Shaman Hwui Li, London 1911.

Duncan M. Derrett, Bhü-bharana, bhū-pālana, bhü-bhojana. An Indian Conundrum, in: Bulletin of the School of Oriental and African Studies 22,1 (1959), 108-123.

John F. FleET, Nilgund Inscription of the Time of Amoghavarsha I.; A. D. 866, in: Epigraphia Indica 6 (1900/01a), 98-108.

69 SCHMiedChen 2014, 125. 
John F. FleEt, Some Records of the Rashtrakuta Kings of Malkhed: The appellations of the Rāshṭrakūṭas of Mālkheḍ, in: Epigraphia Indica 6 (1900/01b), 167-198.

John F. FleEt, Some Records of the Rashtrakuta Kings of Malkhed: The family-name of the Rāshṭrakūṭas of Mālkhẹ̣, in: Epigraphia Indica 7 (1902/03), 214-223.

René Grousset, Die Reise nach Westen oder wie Hsüan-tsang den Buddhismus nach China holte, übers. v. Peter Fischer/Renate Sснмidt, München 1986 (frz. Originalausg. Paris 1929).

Oskar von HinÜBER, Die Kolophone der Gilgit-Handschriften, in: Studien zur Indologie und Iranistik 5/6 (1980), 49-82.

Oskar von HINÜBER, Indische Namen in Zentralasien bis 1000 n. Chr., in: Ernst EICHLER et al. (edd.), Namenforschung. Ein internationales Handbuch zur Onomastik (Handbücher zur Sprach- und Kommunikationswissenschaft 11), Bd. 1, Berlin/New York 1995, 657-665.

Axel Michaels, Der Hinduismus. Geschichte und Gegenwart, München 1998.

Monier Monier-Wiliams, A Sanskrit-English Dictionary, Oxford 1899.

Klaus Mylıus, Geschichte der Literatur im alten Indien (Reclam-Reihe 1021), Leipzig 1983.

Vajeshankar G. Ojнa/Th. von Schtscherbatsкoi, Lunsadi Plates of Siladitya II.[sic!]; [Gupta-] Samvat 350, in: Epigraphia Indica 4 (1896/97), 74-81.

Patrick Olivelle, King, Governance, and Law: Kauțilya's Arthaśāstra. A New Annotated Translation, Oxford/New York 2013.

Annette Schmiedchen, Religious Patronage and Political Power: The Ambivalent Character of Royal Donations in Sanskrit Epigraphy, in: Journal of Ancient Indian History 27 (2010/11), 154-166.

Annette Schmiedchen, Herrschergenealogie und religiöses Patronat: Die Inschriftenkultur der Rāștrakūṭas, Śilāhāras und Yādavas (8. bis 13. Jahrhundert) (Gonda Indological Studies 17), Leiden 2014.

Annette Schmiedchen, Kings, Authors, and Messengers: The Composition of the Maitraka Copper-Plate Charters, in: Bharati Shelat/Thomas Parmar (edd.), New Horizons in Indology (Prof. Dr. H. G. Shastri Commemoration Volume), Ahmedabad 2018, $35-41$.

Rüdiger Schмiтt, Alt- und mittelindoarische Namen, in: Ernst Eichler et al. (edd.), Namenforschung. Ein internationales Handbuch zur Onomastik (Handbücher zur Sprach- und Kommunikationswissenschaft 11), Bd. 1, Berlin/New York 1995, 645-657.

Fred Virkus, Die Könige und das verdorbene Zeitalter - politische Propaganda und Weltzeitaltertheorie im frühmittelalterlichen Indien, in: Das Altertum 42 (1997), 207212. 